In one rase, while the fluid was clear and no organism was fonnd in it, it was fourd in a throat-swab.

An excess of lymphocytes was several times found in a clear flutd that later became purulent.

It was remarkable how few cocci were found as a rule in a smear, and their number had no relation to the state of the pus cells whether degenerated or in good preservation. The pus often seemed to contain nothing but mononuclear or deyenerated cells, but after a long search a large area of polymorphonuclear cells was nearly always eventually found, showing that the mixture of cells was not on regular lines.

In one case the meningococcus was found alive in the fluid after it had been in the incubator for 23 days, but as a rule the organism was very difficult to keep alive on any media more than half that time. It was found that the fluid drawn from the cisterna magna after drath for diagnosis gave better information than that from the lumbar region both in the case of cerebro-spinal fever and tubercular meningitis.

The amsunt of cerebro-spinal fluid in a normal adult is variously stated at 60 c.c. and 200 c.c., but on one occasion a surplus of 75 c.c. was taken from a baby of 9 months with normal measurement of the head, an $t$ this without undue depression of the fontanelle. No harm ever resulted from allowing the flow to continue until normal pressure was reached.

In 16 positive and 2 doubtful cases the fluid remained clear ; all these were mild cases which recovered.

Contaots. - In taking swabs it was found best to abstain from using a tongue depressor, and that if the patient was induced to continue saying "ah," it was easy to introduce West's swab without discomfort to him.

Before inoculating the plates it was found necessary to wipe the glass tube carefully, so is to remove any secretion and to prevent any organisms from the mouth being sown and any inhibition of growth by saliva. Another method was to withdraw the wire upwards for inoculation. The plates received four or five drops of fresh serum and the swab was placed in these when being applied to the surface.

It was remarked that where the contacts had been living together the same flora appeared to a great extent, also that there are usually not more than two kinds of organism on the plate showing the selective nature of the part.

It was ouly possible for want of time to carry out the $23^{\circ}$ incubator and sugar tests. The latter gave trouble. The most satisfactory tests were obtdined by the additions of serum to the media. Positive cases varied very much in the length of time necessary for producing acid-viz., one to six ilays. Growth at $23^{\circ}$ was delayed in some cases till the fifth day.

0 wing to the absence of a systematic agglutinating test the percentage of positives was douhtless too high.

No contacts were known to catch the disease. Duration of the oryanism in a contact was usually less than 17 days, but one lasted for 11 weeks. The duration appeared to be independent of treatment. Out of 14 swabs taken at the commencemert of an atitack 3 were found positive only.

The following table shows the number of positive contacts as they occurred in each 100 swabbed, and the dates of same:-

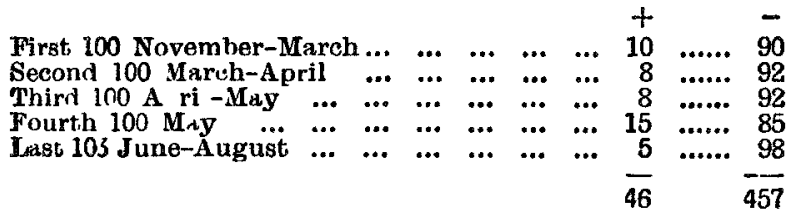

Medico Psychological Association of Great BRINAIN AND IRELAND.-The next general meeting of the association will be held on Thursday, Feb. 15th, at 3 P.M., at 11, Chandos-street, Cavendish-square, London, W., when a paper will be real, entitled " Dreams and their Interpretation, with reference to Freadism," by Dr. Robert ArmstrongJones.

LITERARY INTELLIGENCE.-For the use of medical men engaged in war work, Messrs. J. and A. Churchill have published the following during the week: A sixteenth edition of "Minor Surgery and Bandaging," by Mr. $\mathrm{H}$. Morriston Davies, and a second edition of "Sanitation in War," by Major P. S. Lelean, R.A.M.C. Now illustrations have been inserted in this volume and the whole of the text has been revised.

\section{ON THE TREATMENT OF SCABIES AND SOME OTHER COMMON SKIN AFFEC- TIOMS IN SOLDIERS.}

BY H. G. AD IMSON, M.D. LOND., F.R.O.P. LoND., PHYSICLAN FOR DISEASES OF THF SKIN, ST. BaRThOLO MEW S HOSPITAL HONURARY CUNSUL'TANI' FOR SK IN DISEASES IN MILITARY HOSPITALS IN LUNDUN.

MEDICAL men in charge of patients in military hospitals, convalescent homes, and camps are often called upon to diagnose and treat certain diseases of the skin. Contrary to what one might expect as a result of the conditions under which a soldier lives o , active service, the list of these

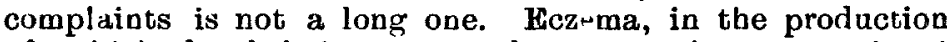
of which local irritants are known to be a prominent factor, is by no means common among soldiers, in spite ot infrequent baths and change of clothing. On the contrary, many men who in civil life have been victims of eczema, have lost that complaint whlle serving in the Army, perhaps as the result of a better state of general health. Neither does one see, as again one might expect to see among those who have been at the front, lichen planus, an affection which in civil life is often caused by stress or nervous worry. The really frequent skin affections of soldiers are comprised among the more common contagious skin diseaves. Pediculosis, scabies, impetigo contayiosa are probably the most prevalent, then certain forms of ringworm. If we a Id to these the eruptions of secondary syphilis and proriasis vulgaris, these half-dozen affections are those with which a military doctor is most likely to meet.

Pediculosis is mainly a complaint of the trenches, and, as "the louse problem of the western front," its management has been fully discussed in the medical journals. Syphilis is a disease which at once passes out of the hand, of the local medical officer to be treated in special hospitals for venereal diseases.

Scabies, impetiyo contagiosa, and to a less extent ringworm, though in a sense trivial complaints, are nevertheless responsible for the temporary invaliding of bundreds, pernaps thousands, of otherwise able-bodied men. Measures for the treatment of these diseaves are therefore worthy of attention. Pooriasis also invalıds many otherwise healthy men and sends them to hospital either because of the extent and consequent discomfort of the eruption, or because the eruption is looked upon with suspicion by the man's companions.

Seabies.

It is a very good rule, when a soldier (as, indeed, a civilian), of whatever rank, complains of itching, to think first of scabies, and to exclude that disease before giving consideration to any other. I c ching at nizht is particularly suggestive of scabies.

One looks between the fingers and about the wrists for " burrows," and on the buttocks, and particularly on the penis, for red raised ridges, the result of burrows which have become inflamed by scratching or infection.

On the fingers and wrists the burrow is seen as a narrow wavy line, geverully black from included dirt, and $\frac{1}{1}$ inch to 1 inch long. Sometimes there is near, but not actually at one end of, the burrow a clear pinhead-sized vesicle-the pearly vesicle-over the roof of which the burrow passes. When examined with a lens the acarus can be seen at one extremitr of the burrow as a whitish speck ike a minute smooth flat pebble imbedded in the skin. When seen it can be easily rem wed by touching it with the point of a darning needle and examined under the microscope in a little liquor potassm, and the diagnosis is certuin once for all. This is the ouly sure way of finding the acarus; to grope for it blindly in the burrow or the pearly vesicle is useless.

As has been stated, burrows sometimes become inflamed, and an "inflamed burrow" forms a red, raised, ridge-like papule, on the crest of which the burrow can be seen on close inspection. The elongated shape of the papule is alone suggestive of scabies, and an "inflamed burrow" on the penis is a sure diagnostic sign of scabies in a man.

But scabies is of ten complicated by $(a)$ impetigo con tagiosa or by (b) eczema, and in either case it may be then less easy to find a tyuical burrow and an acarus.

When complicated by impetigo, the hands and feet particularly are the seat of vesic'es and bullw with clear or turbid contents, together with crusts, erosions, and inflamed burrows; and there may be crusted infiltrated nodules (ecthrma) on the buttocks, and of ten crusts and erosions on other parts, sometimes here and there a small furuncle. 
When eczema complicates scabies there are red, rough, eczematoid areas, sometimes dry and sometimes weeping, on the hauds, arms, thighs, and trunk, masking of ten the burrows of the original complaint. In many instances the eczema is caused by too prolonged use of sulphur applications, but it may also result from constant scratching in scabies of long standing.

In respect to the contagion of scabies, it should be remembered that it is usually in men a venereal disease, but that it may also be conveyed to others by means of things which are handled, such as books, playing-cards, dominoes, and utensils of all sorts.

Ireatment of seabies. - It was said by Hebra 50 years ago that "there is, perhaps, scarcely any other curable disease for which so many and various remedies have been proposed as for scabies. 'Those enumerated in medical works amount to hundreds." Of the treatments which have survived there is none, perhaps, so universally employed to-day as that recommended by Hebra of baths, soap, and sulphur ointment The method of "sulphur fumigations," recently recommended by Major John Bruce and Captain Stanley Hodgson. dates back from the seventeenth century, and it is worthy of remark that Hebra said of this method after a trial in the General Hospital of Vienna, that "the results obtained were not such as to lead to the further adoption of the method, for it was found to set up artificial eczematous eruptions, which so greatly prolonged the treatment that its average duration exceeded four weeks."

The all-important points in dealing with cases of scabies are (1) to make sure of the diagnosis, if possible by finding an acarus ; (2) to then carry out a very thorough treatment for a strictly limited period. Doubt in diagnosis often leads to ineffestual treatment; treatment ineffectual but too long-continued leads to eczema or sulphur dermatitis and still further confuses the diagnosis.

The simplest and most efficacious treatment is as follows :-

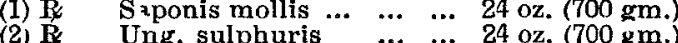

$$
\begin{aligned}
& \text { S. The soap and ointment for three applications. }
\end{aligned}
$$

(1) A hot bath of half-an-hour's duration is taken on three consecutive days. During the bath the body and limbs, especially the hands and wrists and buttocks, are scrubbed with soft soap by a flesh brush.

(2) After each bath the patient himself rubs in the ointment and puts on an old sleeping suit, gloves, and socks and goes to bed, where he remains until it is time for the bath on the next day.

The baths and inunctions must on no account be continued beyond the three days. The patient gets up and dresses af ter the three days and usually requires no further treatment, but is kept under observation for another three days. If, as sometimes happens, some itching continues he is given the following lotion to mop on night and morning.

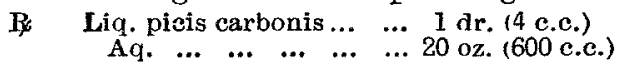

If the treatment bas been thoroughly carried out the patient is cured and free from infection after the three baths and inunctions. If a case is not cured in this way, it is probably not scabies, but either a papular urticaria or chronic eczema. For the former affection a lotion of ordinary vinegar is often efficacious. For the eczema a zinc ointment as follows should be freely applied and all baths forbidden.

$$
\begin{aligned}
& \text { B. } \quad \begin{array}{lllll}
\text { Zinci oxidi... } & \ldots & \ldots & 1 \text { oz. }(30 \mathrm{gm} .)
\end{array} \\
& \begin{array}{lllll}
\text { Pulv amyli } & \ldots & \ldots & 1 \mathrm{oz} .(30 \mathrm{gm} .) \\
\text { Vaselin. } & \ldots & \ldots & \text { ad } & 10 \mathrm{oz} .(300 \mathrm{gm} .)
\end{array}
\end{aligned}
$$

By this method of treating scabies, with one bath and a good supply of hot water, from 12 to 16 men can have treatment each day, or a complete cure for 24 to 32 men per week, and so on, in proportion to the number of baths available. Clothes may be disinfected, but in practice this is found to be unnecessary. Brushing and airing of outside clothes and washing of underclothes suffice.

\section{Impetigo Contagiosa.}

It has been already remarked that impetigo may complicate scabies and that it then attacks particularly the hands, buttocks, and thighs. But it often occurs apart from scabies as single cases or in small epidemics.

Its usual situation is then the face, beard region and scalp, and the fingers. It is of common occurrence as a result of a visit to the barber or from using a public towel It usually begins on the beard region as scattered isolated crusts, which quickly spread on to other parts of the face, about the ears, and sometimes on to the neck and scalp. It is often mistaken for sycosis or for eczema, but it is easily recognised by the appearance of "stuck on" amber-coloured crusts from the size of a solit pea to that of a shilling. Each of these crusts represents the dried serum of a blister, buts the drying takes place so quickly that the original blister is seldom seen, though on removing a crust with forceps there is revealed a raw weeping surface, which is the base of the blister. Frequently there is a phlyctenular whitlow on a finger or thumb around the root of the nail, and there may be crusted patches on the hands or forearms.

This eruption is often wrongly supposed to be of staphylococcal origin, but it is really due to a streptococcal infection. If untreated the infection spreads rapidly, especially in hot climates or warm weather. If effectively treated the eruption may be cured in a few days or a week, but if not rightly dealt with, sooner or later a secondary staphylococcic infection supervenes. The staphylococcus invades the hair follicles of the beard, evebrows, eyelashes, and scalp, and a deep-seated, intractable, sometimes incurable, pustular dermatitis results. On the beard region this staphylococcal infection is known as sycosis, and on the eyelids as blepharitis, but the exactly similar condition on the scalp and eyebrows has no definite name, and is often wrongly called pustular eczema. It might be called sycosis capitis, or chronic impetigo.

Treatment of impetigo contagiosa.-The essential part of the treatment of impetigo is the complete removal of every scrap of crust in order that any antiseptic application may reach the site of the invading micro-organism.

The patient should be made to mop off the crusts with a wad of wool and hot water, and to continue to mop for half an hour or until every crust is removed. A lotion of 1 in 6000 hydrarg. perchlor. is then daubed on for a few minutes and a diluted white precipitate ointment applied (hydrarg. ammon. chlor. $10 \mathrm{gr} .\left(0^{\circ} 6 \mathrm{gm}\right.$.), vaseline $1 \mathrm{oz}$. (30 gm.)). The bathing and application of ointment is repeated several times daily and continued until no fresh crusts are formed. In this way the most extensive eruptions can be cured in a few days. Without the thorough removal of crusts the ointment fails to reach all the infected parts and the eruption continues. With wrong or inefficient treatment 8 secondary staphylococcal infection supervenes and an intractable chronic impetigo or "sycosis" results. If dealt with early a "sycosis" may of ten be quickly cured by staphylococcal vaccines, but where long established vaccines fail, and other treatments, including $X$ rays, may be tried in vain until the man is finally discharged from the Army as incurable.

\section{Ringroorm.}

Ringworm is a third contagious skin complaint which may incapacitate soldiers, though it is less generally prevalent than either scabies or impetigo.

It may occur on the beard region or on the forearms in the form of large disc-like inflammatory plaques with pustulating points as the result of infection from horses, and epidemics of "horse-ringworm" of this sort were at one time prevalent in certain cavalry camps, but have apparently now ceased to occur.

More general forms are ringworm of the groin (tines cruris or Dhobie itch) and eczematoid ringworm of the extremities. Groin ringworm is perhaps more often met with among officers, and ringworm of the toes and feet particularly in hot climates or during warm weather. Ring worm of the groin and the interdigital ringworm may sometimes be associated in the same patient. Ringworm of the toes and feet most calls for attention because it is less generally known and recognised as such. In its mildest form it causes red, dry, or excoriated surfaces between the toes due to peeling off of the horny layers of the epidermis. The red surfaces are sharply margined from the normal skin by an overhanging fringe of epidermis and the generally extend on to the sole of the foot. In cold weather it of ten remains in this condition and causes comparatively little discomfort. In hot weather, and in tropical climates especially, the eruption may spread rapidly and extend over the foot and even up the leg to the knee in the form of blisters and excoriations, sometimes with codema of the leg. Many such cases were seen invalided from Gallipoli.

One of two measures may be adopted in treating any of these forms of ringworm.

(1) The application of an ointment which we owe to Dr. Arthur Whitfield-viz.:

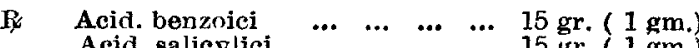

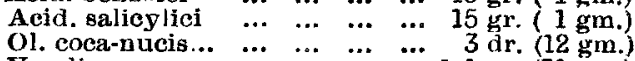

$$
\begin{aligned}
& \begin{array}{lllllll}
\text { Vaselin. } \ldots . . . . & \ldots . & \ldots & \ldots & \ldots & \ldots & \text { ad } 1 \text { oz. }(30 \mathrm{gm} \text {.) }
\end{array}
\end{aligned}
$$

In cases where there is vesication the inunction should be preceded by fomentation with hot water. Many cases quickly clear up with this treatment, but sometimes part of the eruption in the groin, or between the toes, 
o1 on the soles remains obstinate, and for these cases a useful treatment is:-

(2) First thoroughly mop the affected parts with tinctura iodi; then rub on argent. nitratis $10 \mathrm{gr} .(0.6 \mathrm{gm}$.$) , spirit.$ ætheris nitrosi $1 \mathrm{oz}$. (30 gm.). Repeat this treatment if necessary, and apply the benzoic acid ointment between whiles.

For the treatment of psoriasis in soldiers it is but waste of time to try internal remedies. They are generally disappointing, and, in any case, show no results for weeks. It is better to at once apply local remedies.

The following ointment is often successful in removing the eruption :-

\section{Z Hydrarg. ammon. chlor. ... $\quad \ldots \quad 1$ dr. ( 4 gm.)} Liq picis carbonis.. Uny. paraffin. B.P.

$$
\begin{aligned}
& 1 \\
& 6 \text { oz. }(15 \text { c.c. }) \\
& \text { oz. }(180 \text { gm. })
\end{aligned}
$$

S. The ointment to be wril rubbed in twice daily with a piece of flannel. This ointment, which is made with a stiff basis-ung. paraffin.-is usually more effectual than when made with simple vaseline. If this ointment fails, ung. chrysarobini B.P. should be employed, with the usual precautions of avoiding the face, hands, and scalp, and relaxing the treatment if chrysarobin erythema appears at any part. The patien should be kept in bed when chrysarobin olntment is used.

The treatment of p-oriasis will be usually slow, but for most of these complaints it may be said that with prompt and efficient treatment the period of hospitalisation will be reduced to a week or so, while inefficient treatment may prolong that period to many weeks or months, or lead even to eventual discharge of men from the Army with the complaint still uncured. This, then, is the excuse, if such be needed, for venturing to discuss these somewhat banal subjects.

Devonshire-place, $\mathrm{W}$.

\section{BLINDED SAILORS AND SOLDIERS :}

\section{REMARKS ON THE TRAINING AT ST. DUNSTAN'S.}

BR ARNOLD LAWSON, F.R.C.S. ENG.

OPHTHALMIO S'RGEON AND LECIURER ON OPHTHALMIC SURGERY, MIDDLESEX HOSPIPAL; OPHTHALMIC SURGEON TO

$$
\text { SI. DUMSTAN'S HOSTEL. }
$$

THE fact that the great war rapidly developed largely into a trench warfare has caused head injuries to figure very prominently in the casualty lists. One of the after-consequences of many of these head injuries is partial or complete loss of sight, and as a result the war had not been many months in progress before a number of discharged blinded soldiers were thrown on to the nation's charity. As in many other matters the nation was not prepared for this state of things, and St. Dunstan's was the first, as it has now grown to be the final and complete, answer to the urgent cry for help from the sufferers. Everybody now knows that St. Dunstan's was initiated, put into being, and carried on to what it now is by the self-devotion and genius for organisation of Sir Arthur Pearson, who has given the whole of his marvellous energies, and incidentally has largely sacrificed his health, to perfecting a scheme for the training of blinded soldiers and sailors.

St. Dunstan's started just a short 22 months ago in a large house in the Bayswater-road. Thence in March, 1915, it moved to its present quarters in Regent's Park, where on the 15 acres of available land it now lodges about 180 men, and here the greater part of the training is carried out. But St. Dunstan's stands for much more than this. It now includes the Regent's Park College, recently made over by the generosity of the Baptist College Committee, with its possible accommodation for about 200 more men. In addition two large h unses in Portland-place serve as accommodation for blinded officers, and two houses in Paddington are also being used to lodge some of the men for whom there is no available space at St. Dunstan's for the moment. Further, four convalescent homes (two at Brighton, one at Blackheath, and one at Torquay), with accommodation between them for 112 patients, serve a most useful purpose in providing the men with week-end and longer trips to rebuild their health. These homes have proved a very great boon, as numbers of the men suffer a great deal from headache and malaise long after their wounds have healed.

Moreover, the work at St. Dunstan's does not end with the training of the men, but purposes to settle them after training-i.e., to provide homes for them, to set them up in business, and to supervise them after settlement. Thus the
" settlement" and "after-care " departments of St. Dunstan's have grown into a great and responsible undertaking, and the work is of necessity very rapidly increasing. It is a work which requires great organisation, and already has advanced to the stage of portioning the United Kingdom into districts, each with its own supervising secretary and branch establishment.

At the present moment there are 388 blinded soldiers and sailors on the books at St. Dunstan's. Of these, 280 are actually at St. Dunstan's or its attendant convalescent homes, whilst 108 are in hospital either waiting admission or sent into hospital as requiring medical treatment in some form.

For the purposes of admission a man is considered fit whose sight is so injured that he is incapable of leading an independent existence. There are many, therefore, who can distinguish light. though a large majority are absolutely blind. A difficulty has existed in regard to a certain number of cases which are partly or wholly functional-cases of bad "shell shock," as it is loosely called, for example. To sift and apportion the functional and organic elements in many of these cases is a matter of great difficulty, and to train a purely functional blindness as if it were an organic blindness may be the worst possible treatment. However, ways and means have generally been found to deal with these cases, and the convalescent homes have proved very valuable adjuncts in helping to the right decision.

The great factor in the success which has attended St. Dunstan's is the youth of most of the patients. It is far better to go blind young than to lose sight after middle age. The buoyancy of youth, its power of repair, mental as well as physical, and its inherent faculty of living in and for the present without undue inquiry into a remote future, make it possible for blinded youth quickly to pick up the severed threads and start life again. Such elasticity is out of the reach of the aged, and consequently the training of the youthful blind is far easier and far more gratifying in its results than training applied to the old.

At St. Dunstan's the men are all taught to shun self-pity. Commiseration is avoided, and from the start the man is encouraged to accept his lot as an inconvenience and not as a disability. He has got to make the best of it, and the best is a very good one if it is learnt aright. A visit to St. Dunstan's at any time will speedily assure the stranger that this spirit is quickly and cheerfully accepted, for there is no cheerier place in London.

Another and equally important point in the training is the teaching of independence. The blind man instinctively becomes increasingly dependent on others if left to himself and the greatest pains are taken at St. Dunstan's to show the men how to shift as far as possible for themselves. Various simple devices are adopted and after a very short stay the man will be found cheerily going about his own business without a thought of seeking outside help. A more subtle difficulty is the natural "suspicion" of a blind man. Everybody instinctively gauges the value of a word by watching the speaker, and the loss of this faculty of watching weighs very heavily on many blinded people. The feeling of distrust soon wears off at St. Dunstan's in the life of good fellowship amongst others similarly handicapped, aided by the inspiration afforded by the experiences of those who have lived at the hostel for some time.

The actual training of the men occupies a work day of four hours, two hours being given up daily to learning Braille and typewriting, and two hours to the learning of handicrafts or trade. The hours are not long, but the blind man has to visualise everything mentally, and has consequently to concentrate intensely upon all his work. Thus the blind man gets tired much more quickly than the sighted man even when "fit," and very many at St. Dunstan's are anything but "fit." Typing is quickly learnt, and if an "efficiency" test is passed the man on leaving the hostel is presented with a Remington typewriter. Braille presents many difficulties to the older and to the more uneducated men, as also to a good many of those who have had severe head injuries. I am in hopes that a simplified Braille may be devised to meet this need. For a selected few massage, poultry farming, and telephoning form very suitable occupations; but these are not for the majority, who are set to learn simpler things, such as mat-making. basket- and hamper-making, carpentering, or cobbling. Two of these rougher trades are usually learnt by each man. The average time occupied in 